\title{
Analysis on Grammar Patterns of English Textbooks for Middle School Juniors According to Revised Curriculum in 2009
}

\author{
Youn-A Kwon ${ }^{1}$ and Mun-Koo Kang ${ }^{2}$ \\ ${ }^{1,2}$ Dept. of English Education, Kongju National University, 56, Gongjudaehak-ro, \\ Gongju-si, Chung-Nam 32588, Korea \\ 1youna7907@naver.com, ${ }^{2}$ kangmunkoo@hanmail.net
}

\begin{abstract}
This study aims to discover whether language form is appropriately reflected in English textbooks for middle school juniors through comparing and analyzing the grammar type of the textbooks. 5 textbooks which are usually used are selected and analyzed. The results are as follows. First, 5 textbooks commonly allocate the grammar part in isolation after 'afterreading activities' and have the similar number of grammatical items, which is from 19 to 22. Second, the textbooks introduce grammatical items in an inductive way where students comprehend examples first and discover the grammatical rules in common. Last, most of the textbooks introduce appropriate content on the basis of students' level but its order appears different respectively.
\end{abstract}

Keywords: Revised curriculum in 2009, Language form, English textbook, Middle school junior, Grammar pattern

\section{Introduction}

English becomes more important as people have more opportunities to go abroad and to communicate in English in this globalized situation. Accordingly, English education started focusing on communicative competence and suggesting that traditional grammar-based instruction can hinder students from acquiring fluency, whereby communicative language teaching curriculum was introduced in Korean Sixth curriculum at first. However, immersing in solely one part of language is likely to produce side effect at the same time. No one has had a satisfactory answer for the question: is it appropriate to neglect accuracy but to emphasize fluency for Korea, EFL context? As a result, target language acquisition without precise grammatical knowledge did not seem so feasible that communicative function and language form are classified and introduced in the Seventh curriculum.

This study aims to treat 2 inquires. First, what kind of form-focused activity is suggested in the textbook based on the revised curriculum in 2009 and does it accord with the evaluation criterion? Second, do the activities reflect linguistic form suggested in the curriculum in a reliable way? Besides, there remain 2 following limits in this study. First, it might seem implausible to generalize the results due to the fact that it is based on only 5 textbooks for juniors. Second, it doesn't analyze all the content and sentences of each textbook but the linguistic form parts.

\section{Theoretical backgrounds}

Article history:

Received (September 10, 2016), Review Result (November 17, 2016), Accepted (December 10, 2016) 


\subsection{Evaluation criteria of English textbooks}

According to Rivers (1981), a textbook decides the core of instruction and what and how to learn, which means that it is essential for teachers to investigate its quality. Also, the criteria teachers can utilize when they choose the suitable textbook. Skierso (1991) categorized the criteria for textbook evaluation into 7 parts with detailed information; they appear as [Figure 1] pertained to grammar.

\begin{tabular}{|c|c|}
\hline No. & Contents \\
\hline 1 & How is a kernel sentence categorized and emphasized? \\
\hline 2 & How are grammatical rules introduced: deductive or inductive? \\
\hline 3 & Is verbal conjugation summarized in the textbook? \\
\hline 4 & Are linguistic features introduced in the meaningful situation? \\
\hline
\end{tabular}

Figure 1. Skierso's criteria for textbook selection and evaluation (grammar)

\subsection{Necessity of grammar in an English textbook}

One of the Korean public education characteristics is that only officially approved textbooks are allowed to use. It means that foreign data or reference book published in Korea cannot be used, except several autonomous private schools. In other words, students are provided with only textbooks as linguistic inputs from English education. Hence, how textbooks are organized decides whether language learning appears successful or not. Communicative competence in an authentic sense must be the integration of fluency and accuracy. In this light, the textbook, the core of English education, should consist of its factors which prompt not only fluency but also accuracy. Accuracy can be cultivated through learning grammar, which means the textbook has to treat it in a systematic and explicit way.

\section{Content}

\subsection{Subjects}

5 textbooks are analyzed on the basis of grammar parts' items and methods; they are randomly chosen out of the textbooks for middle school juniors based on the revised curriculum in 2009. The subject textbooks' publisher and name of grammar parts appear as [Figure 2] and they are classified with sign A, B, C, D, and E.

\begin{tabular}{|c|c|c|}
\hline Class sign & Publisher & Name of grammar parts \\
\hline A & Neung-Yule & Language Focus \\
\hline B & Dong-A Publilshing & Language in Use \\
\hline C & Mirae-N & Grammar Cinema \\
\hline D & Chun-Jae & Build up \\
\hline E & YBM & Language in Use \\
\hline
\end{tabular}

Figure 2. English textbooks' publisher and name of grammar parts

\subsection{Methods and criteria}

This study discovers how much 5 subject textbooks reflect 'language form required to communicate' suggested in the revised curriculum in 2009 and what sequence they appear and emphasize in via clarifying the construction of grammar parts and grammatical items and 
their frequency. In addition, it is supposed to ascertain whether they accord with Skierso's criteria (1991) and whether they introduce grammar in a deductive way or in an inductive way. [Figure 3] is the table where each example of 'language form required communicating' and the target item are categorized and demonstrated.

\begin{tabular}{|c|c|c|}
\hline No. & Grammatical items & Example \\
\hline 1 & Noun & Sean and Kate are from London. \\
\hline 2 & Determinative & You can choose any color you like. \\
\hline 3 & Tense & They met in the school yesterday. \\
\hline 4 & Pronoun & Which do you like the better, this or that? \\
\hline 5 & Indefinite pronoun & I have three books. One is mine. The others are yours. \\
\hline 6 & Impersonal subject & It's Wednesday. \\
\hline 7 & Tense & She is going to go abroad next year. \\
\hline 8 & Progressive & I'm thinking about the solution. \\
\hline 9 & Perfect & Have you ever been to Florida? \\
\hline 10 & Sentence pattern & The baby cried. [SV] \\
\hline 11 & Preposition & Bill is good at swimming. \\
\hline 12 & Positive degree & She is as tall as her mother. \\
\hline 13 & Comparative & You are a better singer than I am. \\
\hline 14 & Superlative & Kate is the shortest of the three. \\
\hline 15 & Causative verb & I made him carry the box. \\
\hline 16 & To infinitive & I have a book to read. \\
\hline 17 & To infinitive & Ron is furious to hear it. \\
\hline 18 & Gerund & Playing baseball is fun. \\
\hline 19 & Exclamatory sentence & How beautiful she is! \\
\hline 20 & Negation & We didn't enjoy the holiday very much. \\
\hline 21 & Interrogative & Who can answer that question? \\
\hline 22 & Direct narration & He said to me, "Please come at once." \\
\hline 23 & Interrogative + to infinitive & Tell me how to make pizza. \\
\hline 24 & Conditional sentence & If oil is mixed with water, it floats. \\
\hline 25 & Subjunctive mood & If joe had the time, he would go to Spain. \\
\hline 26 & Auxiliary verb & May I borrow your book? \\
\hline 27 & Cooperative conjunction & John plays the guitar, and his sister plays the piano. \\
\hline 28 & Subordinate conjunction & When we arrived, she was talking on the phone. \\
\hline 29 & Conjunction & Ted didn't study at all. Therefore, he failed the test again. \\
\hline 30 & Relative pronoun & The girl who is playing the piano is called Ann. \\
\hline 31 & Post-modifier & Something strange happened last night. \\
\hline 32 & Participle & Walking along the street, I met an old friend. \\
\hline 33 & Absolute participle & Frankly speaking, I failed the test. \\
\hline 34 & Noun phrase & I believe (that) you are mistaken. \\
\hline 35 & Inversion & Not a word did he say. \\
\hline 36 & Existential there & There is a cat. \\
\hline 37 & Discourse & Won't you try again? - Yes, I will try again. \\
\hline 38 & Placeholder & It is cruel to tease animals. \\
\hline 39 & Appositive clause & The fact that Mary was late didn't surprise me. \\
\hline
\end{tabular}



40
Passive
A prize was given to Jane.

Figure 3. Language form required to communicate (Education Ministry, 2011)

\section{Analysis}

\subsection{Grammar item construction}

All of them include 10 chapters originally, but there are 2 more special chapters in E. But, grammatical items are not introduced in special chapters, thereby not existing in the table.

The number of grammatical items appears from 19 to 22, which means there lies no significant differences among them.

Besides, grammar parts are allocated after 'after-reading' activities in all of the subject textbooks.

\subsection{Grammatical items of each textbook}

\subsubsection{Textbook ' $A$ '}

11 items are illustrated; 'to infinitive' is introduced six times, which is excessive; three times of 'sentence pattern'; twice of 'relative pronoun' and 'present perfect'. But 'gerund', 'relative adverb', 'conjunction', 'auxiliary verb', 'positive degree', and 'comparative' are introduced only once, which seems insufficient compared to the most frequent 2 items.

\subsubsection{Textbook ' $B$ '}

13 items are illustrated; 'to infinitive' is introduced four times, which is the most frequent; three times of 'conjunction'; twice of 'sentence pattern', 'relative pronoun', 'auxiliary verb', and 'indefinite pronoun'; once of 'imperative sentence', 'passive', 'present perfect', 'indirect question', 'conditional sentence', 'preposition phrase', and 'impersonal subject'.

\subsubsection{Textbook ' $C$ '}

12 items are illustrated; 'conjunction' is introduced four times, which is the most frequent; three times of 'sentence pattern' and 'to infinitive'; twice of 'relative pronoun'; once of 'gerund', 'auxiliary verb', 'present perfect', 'positive degree', 'imperative sentence', 'passive', 'conditional sentence' and 'preposition', which seem insufficient.

\subsubsection{Textbook ' $D$ '}

12 items are illustrated; 'to infinitive' is introduced four times, which is the most frequent; three times of 'sentence pattern' twice of 'gerund' and 'present perfect'; once of 'tag question', 'conjunction', 'present participle', 'comparative', 'superlative', 'relative pronoun', 'passive', and 'conditional sentence'.

\subsubsection{Textbook ' $E$ '}

12 items are illustrated; 'to infinitive' and 'conjunction' are introduced four times, which is the most frequent; twice of 'sentence pattern' and 'relative pronoun'; once of 'superlative', 'material noun', 'comparative', 'present perfect', 'exclamatory sentence', 'passive', 'conditional sentence', and 'linking verb'. 


\subsection{Consequences}

Features of grammatical items introduced in the 5 textbooks are as follows. They include 10 chapters in common. The number of grammatical items vary from 19 to 22: 19 of D, 22 of $\mathrm{B}$, and 20 of $\mathrm{A}, \mathrm{C}$, and $\mathrm{E}$. All of them are allocated after 'after-reading' activities. Also, grammar instruction is performed in the same way: discover learning where they attempt to find out a grammatical rule after studying some examples of target structure. In this way, learners discover the rule on their own and participate in it actively. But, the number of examples appears insufficient; three sentences at most. It can be criticized in that learns might waste their time when they discover the grammatical rule on their own.

\section{Conclusion and suggestion}

This study aims to discover whether language form is appropriately reflected in English textbooks for middle school juniors through comparing and analyzing the grammar type of the textbooks. The consequences are as follows.

First, grammar parts are allocated after 'after-reading' activities in all of the subject textbooks. The number of grammatical items appears from 19 to 22, which means there lies no significant differences among them. Students are likely to learn 2 grammatical items per 1 chapter, which is not that much stressful.

Second, grammar instruction is performed in the same way: discover learning where they attempt to find out a grammatical rule after studying some examples of target structure. In this way, learners discover the rule on their own and participate in it actively. But, the number of examples appears insufficient; three sentences at most. It can be criticized in that learns might waste their time when they discover the grammatical rule on their own.

Third, most of the textbooks introduce target structure according to the students' level. But, when it comes to sequence, it is supposed to be revised. For example, a relatively difficult item such as 'relative pronoun' is introduced in chapter 2 of textbook ' $A$ ' and ' $b$ ' and in chapter 5 of textbook ' $C$ ' and ' $E$ ' before other items. Also, 'passive' is located in chapter 3 of textbook ' $\mathrm{A}$ ' and in chapter 4 of textbook ' $\mathrm{B}$ '.

Based on the consequences mentioned above, suggestions to set the right direction for development of English textbook are as follows. To begin, it is essential to introduce various language form, not overlapping items, which are included in curriculum because students are likely to develop their cognitive competence and learning strategies through attempting to complete various grammar tasks. Also, sufficient examples including language form should be provided so that learners can infer and acquire it without explanation in mother language. It affords for learners to study efficiently compared to the existing surroundings where they have to do so with solely few examples. Last, grammatical items should be taught in order: from easy items to difficult ones, even though it is not definitely classified. It is expected to unburden learners in studying grammar. Therefore, reasonable criteria for setting its sequence should be prepared. 
Analysis on grammar patterns of English textbooks for middle school juniors according to revised curriculum in 2009

\section{References}

[1] Education Ministry, "Educational curriculum of English," Seoul: Education Ministry, (2011)

[2] S.K. Kim, "Middle School English 2," Seoul: Dong-A Publilshing, (2013)

[3] I.D. Kim, Middle School English 2," Seoul: Neung-Yule Education, (2014)

[4] D.B. Bae, "Middle School English 2," Seoul: Mirae-N, (2013)

[5] J.H. Shin, "Middle School English 2," Seoul: YBM, (2013)

[6] J.Y. Lee, "Middle School English 2," Seoul: Chun-Jae, (2013)

[7] W.M. Rivers, "Teaching foreign language skills," Chicago, IL: University of Chicago Press

[8] A. Skierso, "Textbook selection and evaluation," In M. Celce-Murcia (Ed.), Teaching English as a second of foreign language (pp.432-453) New York: Newbury House 